\title{
Microvascular Angina Accompanied by Epicardial Coronary Artery Spasm
}

\author{
Masashi Horimoto, Hitoshi Sakuragi*, Takashi TakenakA*, Hitoki InouE* and Keiichi Igarashi*
}

\begin{abstract}
A case of microvascular angina accompanied by coronary artery spasm is described. A 54-year-old woman had anginal pain at rest and during exercise. Both exercise testing and rapid atrial pacing caused significant ST depression in the inferior and all precordial leads. Exercise thallium myocardial scintigraphy was negative despite similar ST depressions. Coronary angiography revealed insignificant stenoses of the left anterior descending coronary artery after the injection of nitrate. Intracoronary acetylcholine provoked diffuse spasm of the artery with concurrent myocardial lactate production. Coronary flow reserve assessed with papaverine was 2.75 . The combined use of amlodipine and high-dose nicorandil was effective for the treatment of angina.

(Internal Medicine 41: 216-220, 2002)
\end{abstract}

Key words: acetylcholine, coronary flow reserve, amlodipine, nicorandil

\section{Introduction}

Microvascular angina is mainly caused by reduced vasodilator capacity of the coronary small vessels. This angina is characterized as typical chest pain mostly at exercise, a positive exercise test with electrocardiographic ST-segment depression, normal coronary arteriograms and reduced coronary flow reserve (1-5). Although this type of angina is unassociated with epicardial coronary artery spasm, we describe a rare case of microvascular angina accompanied by coronary artery spasm in this report. The drug efficacy for the angina is also discussed.

\section{Case Report}

A 54-year-old woman was admitted to our hospital in November 1998 because of anginal pain at rest and during exercise. She had experienced chest pain at night or in the early morning since July 1995 and had developed exertional angina in August 1998. She had no past medical history, no family history of coronary artery disease, and no coronary risk factors. Physical examination on admission showed no abnormalities. Her blood pressure was $122 / 74 \mathrm{mmHg}$ and pulse was regular at $64 \mathrm{bpm}$. Laboratory data revealed no abnormalities and chest X-ray was also normal. However, an electrocardiogram at rest showed small or inverted T-waves in the inferior and all precordial leads (Fig. 1). Echocardiography showed no hypertrophy or asynergy of the left ventricle, and no valvular abnormalities. A treadmill exercise test caused chest pain with significant ST-segment depression in the inferior and all precordial leads (Fig. 1). Exercise thallium myocardial scintigraphy revealed no perfusion defects, despite the appearance of chest pain with similar ST-segment depressions.

Baseline coronary angiography revealed a 50\% narrowing at the ostium of the left anterior descending coronary artery (LAD) (Fig. 2A). Injection of $2.5 \mathrm{mg}$ of isosorbide dinitrate into the left coronary artery resolved the narrowing (Fig. 2B), suggesting the presence of coronary artery spasm. The artery showed $25 \%$ and $50 \%$ organic stenoses at its proximal and mid portions, respectively. The right coronary artery showed $25 \%$ stenoses at its mid and distal portions after the nitrate injection into the artery. Because of the exertional angina without significant coronary stenoses and the spontaneous coronary artery constriction, we suspected microvascular angina accompanied by coronary artery spasm. To first verify microvascular angina, rapid atrial pacing with concurrent coronary angiography was performed. Right atrial pacing at a rate of $140 \mathrm{bpm}$ provoked chest pain with $0.2 \mathrm{mV}$ of ST-segment depression and T-wave inversion in the inferior and all precordial leads (Fig. 3) in the absence of epicardial coronary spasm (Fig. 4), which suggested microvascular angina.

To verify the presence of coronary artery spasm, graded doses of $\mathrm{ACh}(20,50$, and $100 \mu \mathrm{g})$ in $5 \mathrm{ml}$ of saline were infused in 20 seconds into the left main coronary artery on a separate day after informed consent was obtained from the patient. Blood was sampled from the left main coronary artery and the great cardiac vein to determine the arteriovenous difference in lactate concentration during ST-segment changes with

From the Division of Cardiology, Chitose City General Hospital, Chitose and **the Division of Cardiology, National Sapporo Hospital, Sapporo Received for publication June 18, 2001; Accepted for publication December 3, 2001

Reprint requests should be addressed to Dr. Masashi Horimoto, the Division of Cardiology, Chitose City General Hospital, 1-11 Shinonome-cho, Chitose, Hokkaido 066-8550 


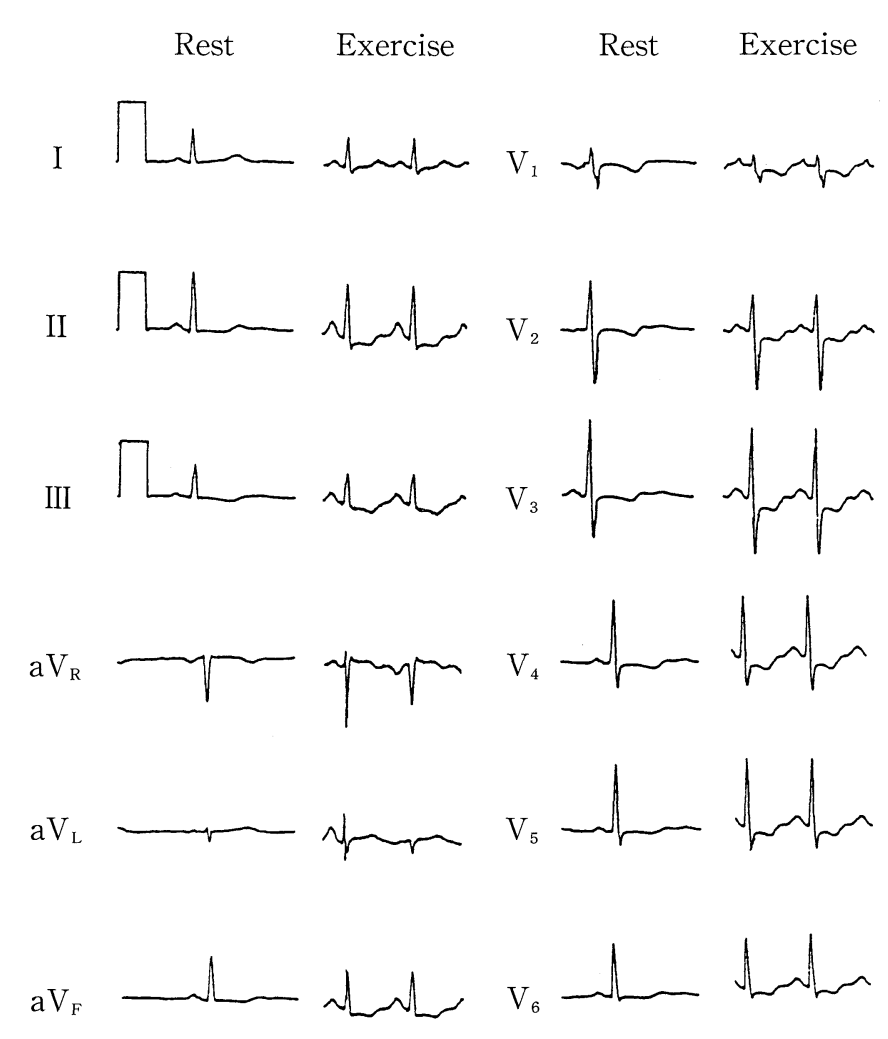

intracoronary ACh. A Doppler guide wire of 0.014 inch in diameter was advanced into the mid portion of the LAD to measure blood flow velocity. Coronary flow reserve was determined as the ratio of maximum average peak velocity after the intracoronary injection of $10 \mathrm{mg}$ of papaverine to the average peak velocity at baseline.

The baseline electrocardiogram showed small or flattened T-waves in the inferior and precordial leads (Fig. 5) and coronary angiograms revealed a moderate stenosis at the mid portion of the LAD (Fig. 6A). The injection of $20 \mu \mathrm{g}$ and $50 \mu \mathrm{g}$ of ACh did not cause chest pain, ST-segment changes or coronary spasm. However, $100 \mu \mathrm{g}$ of ACh caused chest pain with slight ST-segment elevation in leads $\mathrm{V}_{2}-\mathrm{V}_{3}$ (Fig. 5) and intense constriction of the $\mathrm{LAD}$ at its just proximal and distal portions (Fig. 6B). Myocardial lactate production did not occur with 20 or $50 \mu \mathrm{g}$ of ACh, but was detected with $100 \mu \mathrm{g}$ of ACh. Lactate concentrations in the left coronary artery and the great cardiac vein at baseline were 5.7 and $3.9 \mathrm{mg} / \mathrm{dl}$, respectively, whereas

Figure 1. A resting electrocardiogram showed low voltage or inverted T-waves in the inferior and precordial leads. During treadmill exercise test, ST-segment depression occurred in the inferior and precordial leads.

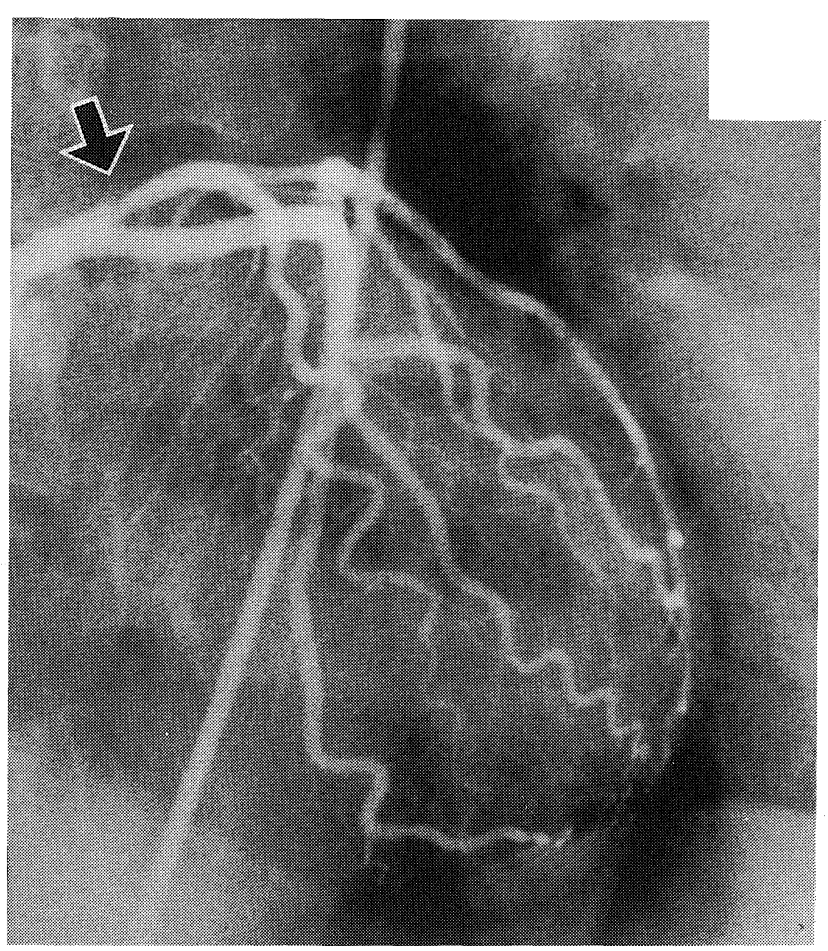

A

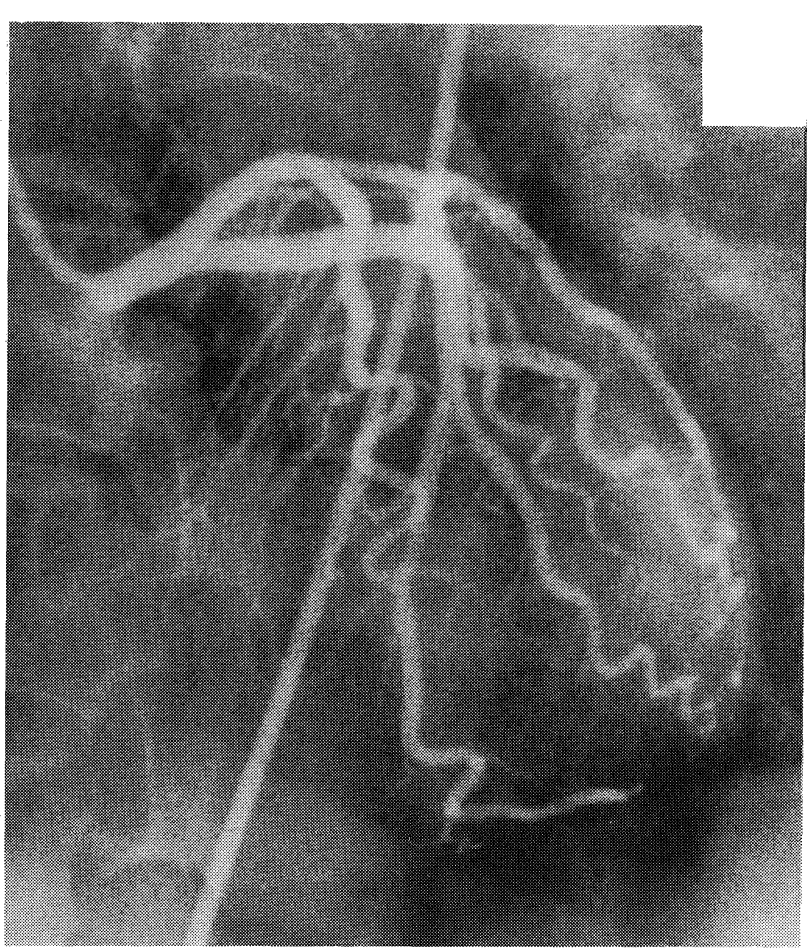

$\mathrm{B}$

Figure 2. Baseline coronary angiogram (straight cranial view) revealed 50\% narrowing at the ostium of the left anterior descending coronary artery (arrow in $A)$. The narrowing resolved with intracoronary nitrate $(B)$. 


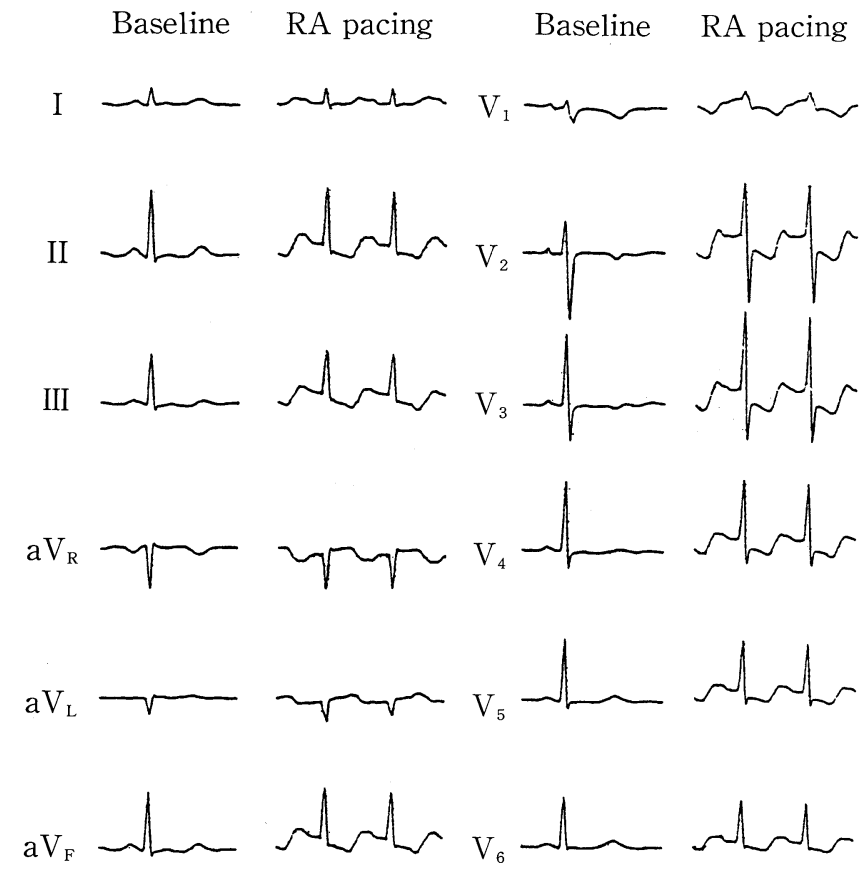

Figure 3. Rapid right atrial (RA) pacing caused electrocardiographic ST-segment depression and T-wave inversion in the inferior and precordial leads.

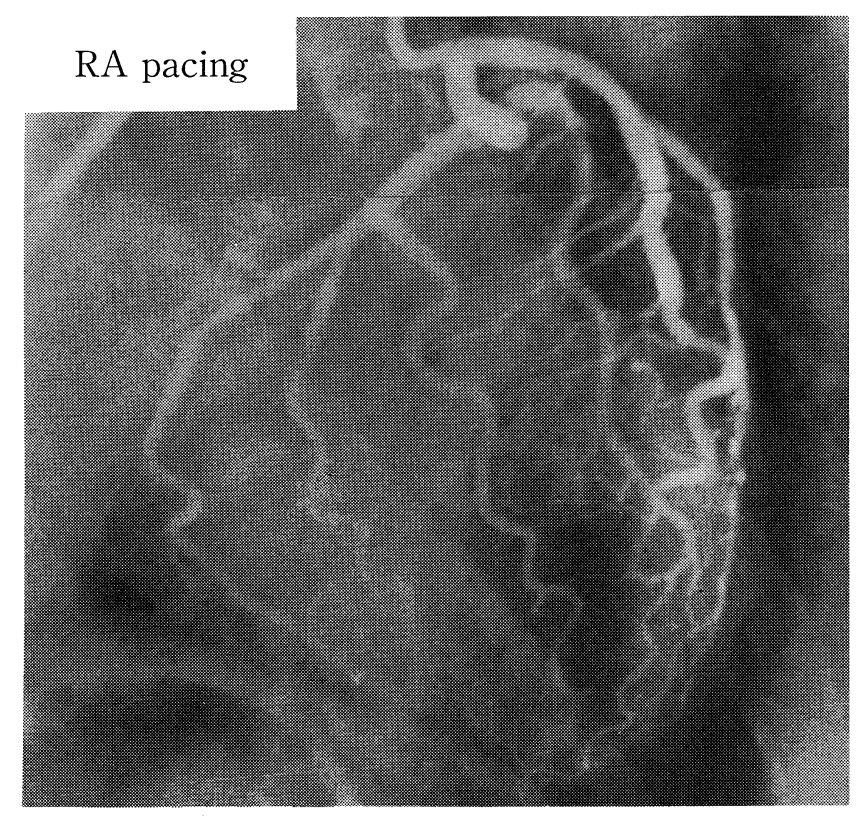

Figure 4. A left coronary angiogram at rapid right atrial (RA) pacing showed no significant coronary stenosis or spasm.

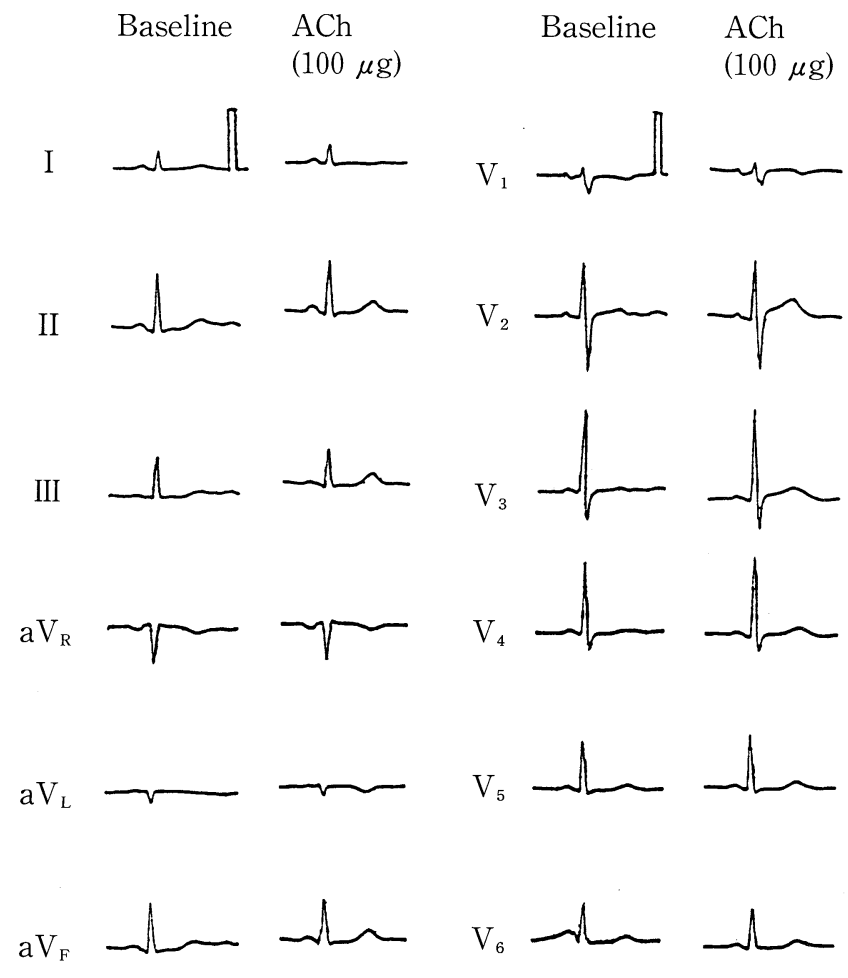

Figure 5. A baseline electrocardiogram was almost normal but slight ST-segment elevation in $V_{2}-V_{3}$ was noted with intracoronary injection of $100 \mu \mathrm{g}$ of acetylcholine.

the concentrations during the injection of $100 \mu \mathrm{g}$ of ACh were 6.3 and $8.6 \mathrm{mg} / \mathrm{dl}$, respectively. This indicated the presence of myocardial ischemia due to the spasm of the LAD despite the minimal ST-segment elevation in leads $\mathrm{V}_{2}-\mathrm{V}_{3}$. The obtained coronary flow reserve was 2.75 . Thus, the diagnosis of microvascular angina accompanied by epicardial coronary artery spasm was most likely.

Drug efficacy for the angina was assessed by serial treadmill exercise testing using the Bruce protocol. To prevent the occurrence of coronary artery spasm during the test, $5 \mathrm{mg} /$ day of amlodipine was included in the therapy. The time from the beginning to the development of $0.1 \mathrm{mV}$ of ST-segment depression during the test was defined as exercise duration. Exercise testing was performed at least 5 days after the administration of each drug. The results are summarized in Table 1. Aminophylline, doxazosin, long-acting isosorbide mononitrate, and verapamil were ineffective in increasing exercise duration, while bisoprolol, long-acting nifedipine, and low-dose nicorandil were effective. However, high-dose nicorandil (30 $\mathrm{mg} /$ day) was the most effective. The patient has been almost free of rest and exertional angina with the combined use of amlodipine and high-dose nicorandil. 


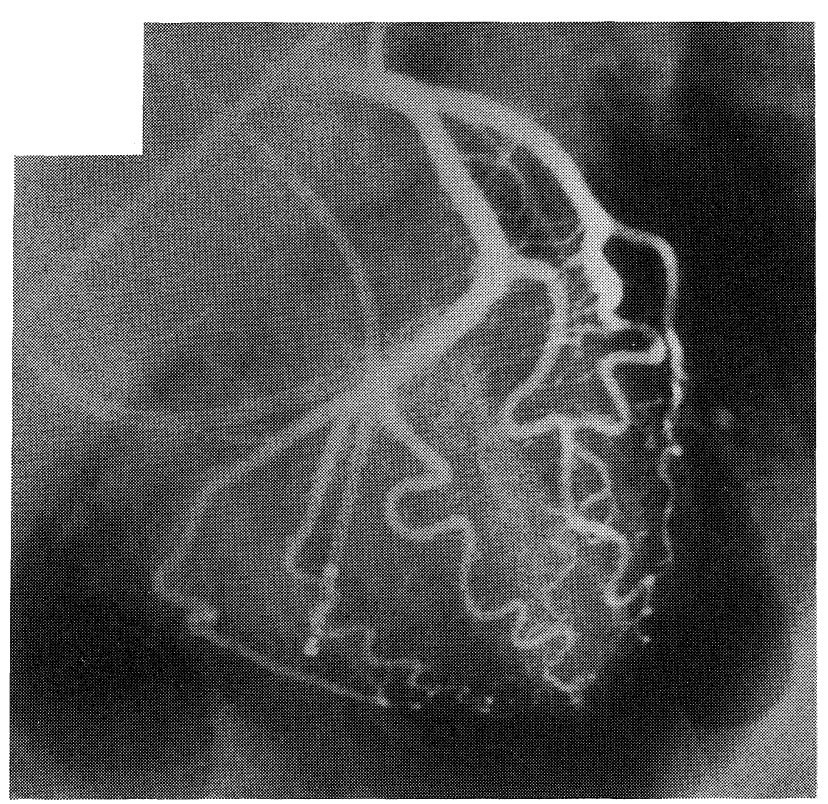

A

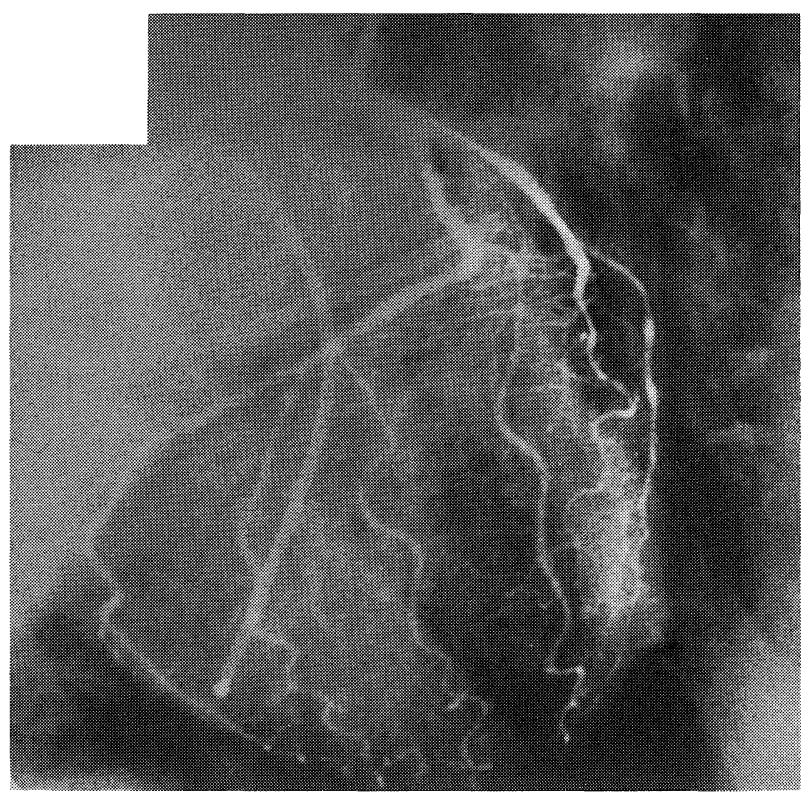

$\mathrm{B}$

Figure 6. A moderate stenosis at the mid portion of the left anterior descending coronary artery is shown at baseline (A, caudally-tilted right anterior oblique $30^{\circ}$ view). Intense constriction of the just proximal and distal portions of the artery occurred after the injection of $100 \mu \mathrm{g}$ of acetylcholine (B).

Table 1. Drug Efficacy for Exercise Duration

\begin{tabular}{llc}
\hline Drugs & Exercise duration & $\mathrm{RPP}(\times 100)$ \\
\hline None & $2 \mathrm{~min} 45 \mathrm{sec}$ & 201 \\
Amlodipine (5 mg/day) & $3 \mathrm{~min} 30 \mathrm{sec}$ & 302 \\
\hline In addition to amlodipine (5 mg/day) & & \\
Aminophylline (250 mg, DIV) & $3 \mathrm{~min} 0 \mathrm{sec}$ & 173 \\
Doxazosin (2 mg/day) & $3 \mathrm{~min} 24 \mathrm{sec}$ & 192 \\
Long-acting ISMN (40 mg/day) & $3 \mathrm{~min} 40 \mathrm{sec}$ & 246 \\
Verapamil (120 mg/day) & $3 \mathrm{~min} 41 \mathrm{sec}$ & 198 \\
Bisoprolol (5 mg/day) & $4 \mathrm{~min} 21 \mathrm{sec}$ & 190 \\
Long-acting nifedipine (20 mg/day) & $4 \mathrm{~min} 39 \mathrm{sec}$ & 211 \\
Nicorandil (15 mg/day) & $4 \mathrm{~min} 41 \mathrm{sec}$ & 202 \\
Nicorandil (30 mg/day) & $6 \mathrm{~min} 12 \mathrm{sec}$ & 246 \\
\hline
\end{tabular}

RPP: rate-pressure product at ST segment depression of $0.1 \mathrm{mV}$, ISMN: isosorbide mononitrate, DIV: intravenous drip infusion.

\section{Discussion}

Microvascular angina has been defined as chest pain, mostly occurring at exercise with concomitant ST-segment depression, normal coronary angiograms and reduced coronary flow reserve (1-5). Patients with systemic hypertension, cardiomyopathy or valvular heart disease are excluded from the diagnosis of this type of angina. The angina is reproducible by exer- cise testing and rapid atrial pacing, and is generally unassociated with coronary artery spasm. The mechanism responsible for microvascular angina is believed to be impaired coronary vasodilator capacity caused by inappropriate constriction of the coronary microvessels and an attenuated response to vasodilator stimuli such as atrial pacing, exercise, dipyridamole, and papaverine (2-4). The present patient met the criteria for microvascular angina with respect to typical chest pain with STsegment depression during exercise and atrial pacing, but did 
not meet it in terms of the presence of a moderate coronary stenosis. However, the moderate stenosis of the LAD in our patient was unlikely a cause of exertional angina. This was because no perfusion defects were shown in exercise thallium myocardial scintigrams and the ST-segment depression during exercise and atrial pacing was too diffuse to account for the myocardial ischemia in the LAD territory.

The intense and diffuse constriction of the LAD in response to $100 \mu \mathrm{g}$ of $\mathrm{ACh}$, which led to myocardial lactate production, was considered as coronary artery spasm rather than coronary constrictor response to a high dose of ACh. This was because the patient had anginal pain at rest and showed focal and spontaneous constriction of the LAD. A previous study demonstrated that the response of angiographically normal coronary segments to ergonovine was similar between patients with microvascular angina, noncardiac chest pain, or coronary artery disease (5). This indicates that there is no predisposition of the epicardial coronary artery to spasm in patients with microvascular angina. Therefore, microvascular angina accompanied by epicardial coronary artery spasm seems extremely rare.

The coronary flow reserve in our patient appeared to be reduced and coincided with the value previously reported in microvascular angina (6). As myocardial lactate production during pacing stress test has been noted in only 0 to $37 \%$ of patients with microvascular angina $(1,7)$, the lactate production is not adopted as a diagnostic criterion of the angina. The diagnosis of microvascular angina in the present case is most likely but may be still indefinite, because myocardial lactate production, i.e., myocardial ischemia during the rapid atrial pacing and ST-segment depression was not evaluated.

Appropriate medication for microvascular angina remains elusive. Ca-blockers $(8,9), \beta$-blockers (10), and nicorandil (11), and aminophylline (12) have been shown to be effective in increasing ischemic threshold defined as exercise duration, while nitrates (13) and $\beta$-blockers (14) were ineffective. Our case demonstrated that nifedipine, bisoprolol, and nicorandil were effective for prolongation of exercise duration, while aminophylline and verapamil were not (Table 1). Since a relatively large dose of nicorandil was the most effective, this drug should be used in a large dose for the treatment of microvascular angina that is refractory to various drugs.

\section{References}

1) Greenberg MA, Grose RM, Neuburger N, Silverman R, Strain JE, Cohen MV. Impaired coronary vasodilator responsiveness as a cause of lactate production during pacing-induced ischemia in patients with angina pectoris and normal coronary arteries. J Am Coll Cardiol 9: 743-751, 1987.

2) Cannon RO, Watson RM, Rosing DR, Epstein SE. Angina caused by reduced vasodilator reserve of the small coronary arteries. J Am Coll Cardiol 1: 1359-1373, 1983.

3) Cannon RO, Leon MB, Watson RM, Rosing DR, Epstein SE. Chest pain and normal coronary arteries: Role of small coronary arteries. Am J Cardiol 55: 50B-60B, 1985.

4) Cannon RO, Epstein SE. Microvascular angina as a cause of chest pain with angiographically normal coronary arteries. Am J Cardiol 61: 13381343, 1988.

5) Kaski JC, Tousoulis D, Galassi AR, et al. Epicardial coronary artery tone and reactivity in patients with normal coronary arteriograms and reduced coronary flow reserve (syndrome X). J Am Coll Cardiol 18: 50-54, 1991.

6) Chauhan A, Mullins PA, Petch MC, Schofield PM. Is coronary flow reserve in response to papaverine really normal in syndrome $X$ ? Circulation 89: 1998-2004, 1994.

7) Camici PG, Marraccini P, Lorenzoni R, et al. Coronary hemodynamics and myocardial metabolism in patients with syndrome $\mathrm{X}$ : Response to pacing stress. J Am Coll Cardiol 17: 1461-1470, 1991.

8) Cannon RO, Watson RM, Rosing DR, Epstein SE. Efficacy of calcium channel blocker therapy for angina pectoris resulting from small-vessel coronary artery disease and abnormal vasodilator reserve. Am J Cardiol 56: 242-246, 1985.

9) Montorsi P, Cozzi S, Loaldi A, et al. Acute coronary vasomotor effects of nifedipine and therapeutic correlates in syndrome X. Am J Cardiol 66: 302-307, 1990.

10) Bugiardini R, Borghi A, Biagetti L, Puddu P. Comparison of verapamil versus, propranolol therapy in syndrome X. Am J Cardiol 63: 286$290,1989$.

11) Chen J-W, Lee W-L, Hsu N-W, et al. Effects of short-term treatment of nicorandil on exercise-induced myocardial ischemia and abnormal cardiac autonomic activity in microvascular angina. Am J Cardiol 80: 3238, 1997.

12) Emdin M, Picano E, Lattanzi F, L'Abbate A. Improved exercise capacity with acute aminophylline administration in patients with syndrome $\mathrm{X}$. J Am Coll Cardiol 14: 1450-1453, 1989.

13) Lanza GA, Manzoli A, Bia E, Crea F, Maseri A. Acute effects of nitrates on exercise testing in patients with syndrome $\mathrm{X}$. Clinical and physiological implications. Circulation 90: 2695-2700, 1994.

14) Galassi AR, Kaski JC, Pupita G, Vejar M, Crea F, Maseri A. Lack of evidence for alpha-adrenergic receptor-mediated mechanisms in the genesis of ischemia in syndrome X. Am J Cardiol 64: 264-269, 1989. 